\title{
PENGARUH DIMENSI, MUATAN TERHADAP JUMLAH BERAT YANG DIIJINKAN MOBIL BAK MUATAN TERBUKA
}

\author{
Ir. Juliaman Pangaribuan, M.Si \\ Dosen STTD \\ Jl. Raya Setu No. 89, Cibuntu, \\ Cibitung, Bekasi 17520 \\ Telp./Fax : (021) 8254640
}

\author{
Abadi Sastrodiyoto, SH, MH \\ Dosen STTD \\ J1. Raya Setu No. 89, Cibuntu, \\ Cibitung, Bekasi 17520 \\ Telp./Fax : (021) 8254640
}

\author{
Ir. Santausa Purnama, MM \\ Dosen STTD \\ Jl. Raya Setu No. 89, Cibuntu, \\ Cibitung, Bekasi 17520 \\ Telp./Fax : (021) 8254640
}

\author{
Nur Aini Boer, SE \\ Dosen STTD \\ J1. Raya Setu No. 89, Cibuntu, \\ Cibitung, Bekasi 17520 \\ Telp./Fax : (021) 8254640
}

\author{
Sudirman Anggada, MT \\ Instruktur STTD \\ Jl. Raya Setu No. 89, Cibuntu, \\ Cibitung, Bekasi 17520
}

Telp./Fax : (021) 8254640

\begin{abstract}
ABSTRAK
Berbagai tipe dan ukuran kendaraan mobil barang setiap hari beroperasi di jalan, mulai dari truk dengan gandar tunggal sampai dengan gandar tandem, triple serta dalam bentuk kereta tempelan dan gandengan telah diberikan izin beroperasi membawa berbagai macam komoditi dan hasil industri, namun sangat disayangkan perkembangan teknologi otomotif ini tidak diimbangi oleh pengetahuan dan informasi tentang peraturan dan dasar hukum tentang perancangan suatu desain kendaraan tertentu, yang pada akhirnya mengarah pada pelanggaran dimensi dan muatan dari kendaraan tersebut.

Penelitian dilakukan melakukan pengumpulan data lapangan terkait dengan spesifikasi sumbu kendaraan barang dan jumlah berat yang diijinkan serta kesesuaian data yang berasal dari Jembatan Timbang untuk melihat fakta-fakta pelanggaran yang terjadi terkait dengan dimensi dan muatan kendaraan barang. Kendaraan barang yang menjadi objek pengukuran yaitu sampel kendaraan barang dengan beragam konfigurasi sumbu yang melakukan pengukuran di Jembatan Timbang Balong Gandu, Jawa Barat. Tahapan analisis terhadap hasil pengumpulan data lapangan yaitu analisa konfigurasi sumbu, analisa dimensi kendaraan, analisa dimensi bak muatan terbuka, analisa persentase beban sumbu, analisa daya rusak (damage factor) serta analisa perencanaan ukuran bak muatan terbuka menurut massa jenis komoditas.

Berdasarkan hasil analisis didapatkan beberapa hipotesa atau temuan terhadap pelanggaran dimensi kendaraan khususnya kendaraan jenis III yaitu sebesar 4.438 dimensi Rear Over Hang atau sebesar $73 \%$ dari wheelbase. Untuk mengatasi permasalahan tersebut direkomendasikan untuk membuat batas ketinggian muatan pada kendaraan barang sesuai dengan jenis muatan yang diangkut yaitu 0,85 meter untuk barang curah, 1,5 meter untuk hasil bumi, dan 2 meter berdasarkan jenis komoditas lain.
\end{abstract}

Kata kunci : Kendaraan Barang, Dimensi, Muatan, Damage Factor

\begin{abstract}
Vehicles as a means to transport freight commodity desperately needed by the people. Basically it has been regulated by the Government regarding the dimensions and the specifications of the vehicle, particularly vehicle car stuff. But the reality in the field, there are still many violations either shape or length, width and height. Many different types and sizes of car vehicle items operate on the road every day, ranging from single axle truck with up with triple axle tandem, as well as in the glue and gandengan have been given permission to operate brings a wide range of
\end{abstract}


commodities and industrial results, but unfortunately the development of automotive technology is not offset by the knowledge and information about the regulatory and legal basis of the design of a specific vehicle design, which ultimately leads to violation of dimensions and charge from the vehicle.

Doing research do field data collection related to the vehicle axis specification of goods and amount of weight are permitted as well as the suitability of the data originating from the bridge Weigh to see facts of violations related to the dimensions of the vehicle and charge stuff. Goods vehicle that became the object of measurement i.e. goods vehicles with various sample configuration that axis measurements in Gandu Balong Weigh Bridge, West Java. The stage of the analysis of the results of the data collection of the field that is the axis of the configuration analysis, analysis of vehicle dimensions, dimensional analysis, the analysis of charge open tubs percentage load fuse, power analysis of damage (damage factor) as well as the analysis of planning the size of the tub is open according to the payload mass types of commodities.

Based on the results of the analysis of the obtained some findings or hypotheses against the dimensions of the vehicle in particular vehicle type III that is amounted to 4,438 dimensions Rear Over Hang or amounting to $73 \%$ of the wheelbase. To overcome these problems it is recommended to make a charge on the vehicle height limit of goods in accordance with the types of content that are transported, namely bulk goods to 0.85 meters, 1.5 meters to produce, and 2 meters based on other types of commodities.

Key Words : Goods Vehicles, Dimensions, Payload, Damage Factor

\section{PENDAHULUAN}

\section{A. Latar Belakang}

Transportasi didefinisikan sebagai proses perpindahan orang dan atau barang dari suatu tempat ke tempat lain. Jalan sebagai salah satu prasarana transportasi darat dan perannya saat ini masih dipandang sebagai prasarana paling efisien dibandingkan dengan yang lainnya, karena jalan masih mempunyai keunggulan dalam faktor aksesibilitas dan mobilitas. Karena itu, prasarana jalan dari waktu ke waktu mengalami pembebanan (volume lalu lintas) yang terus meningkat, dengan adanya geometrik jalan yang ada penataan muatan barang khususnya tidak melebihi dimensi kendaraan yang telah ditetapkan pada suatu ruas jalan pada wilayah tertentu.

Mengacu pada Undang-Undang Lalu Lintas Angkutan Jalan No. 22 Tahun 2009 dan Peraturan Pemerintah Nomor 55 tahun 2012 serta petunjuk teknis dari Direktorat Jenderal Perhubungan Darat, mengenai ketentuan Kendaraan yang menyangkut Dimensi, berat beban pada gandar serta perancangan konstruksi kendaraan. Dengan demikian dimensi kendaraan yang diizinkan adalah panjang kendaraan $(9.000 \mathrm{~mm}-18.000 \mathrm{~mm})$, lebar kendaraan $(2.100 \mathrm{~mm}-2.500 \mathrm{~mm})$, tinggi kendaraan $(3.500 \mathrm{~mm}-4.200 \mathrm{~mm})$. Dengan telah ditetapkannya dimensi kendaraan yang disediakan pada kelas jalan tertentu (kelas I, II dan kelas III) sehingga diketahui berapa ukuran dimensi kendaraan yang ada dilapangan, namun dikarenakan banyak terjadinya perubahan fungsi dan perubahan dimensi serta kemajuan pembuatan bak muatan terbuka pada kendaraan barang yang ada. 
Maka potensi terjadinya pelanggaran dimensi kendaraan yang mempengaruhi kestabilan kendaraan sangat mungkin terjadi dilapangan.

\section{B. Identifikasi Masalah}

1. Teknologi akan sarana transportasi yang terus berkembang pesat, berakibat pada perubahan desain kendaraan yang dimensinya tidak sesuai dengan aturan yang sudah ditetapkan Direktorat Jenderal Perhubungan Darat, khususnya pada kendaraan barang jenis mobil bak muatan terbuka konfigurasi sumbu 1.2 dan 1.22 .

2. Adanya mobil bak muatan terbukakonfiguasi 1.2 dan 1.22 yang tidak sesuai ketentuan, baik dalam segi batas muatan, berat muatan maupun dimensi bak muatan serta penataan muatan.

3. Terjadinya muatan berlebih yang masih belum diperhatikan secara optimal oleh pemerintah, yang apabila di biarkan akan menyebabkan kerusakan jalan dan kemungkinan kecelakaan.

\section{Perumusan Masalah}

Untuk memperoleh gambaran yang jelas tentang permasalahan yang akan diteliti, maka permasalahan dalam penelitian ini dirumuskan sebagai berikut:

1. Apakah terdapat pengaruh dimensi terhadap jumlah berat yang diijinkan mobil bak muatan terbuka?

2. Apakah terdapat pengaruh muatan terhadap jumlah berat yang diijinkan mobil bak muatan terbuka?

3. Apakah terdapat pengaruh dimensi,muatansecara bersama-sama terhadap jumlah berat yang diijinkan mobil bak muatan terbuka?

\section{Batasan Masalah}

Agar pembahasan dalam penulisan penelitian lebih terarah maka perlu dilakukan pembatasan masalah sebagai berikut :

1. Kegiatan penelitian dikhususkan pada Mobil Bak Muatan Terbuka Konfigurasi Sumbu 1.2 dan 1.22

2. Untuk pembahasan penelitian menggunakan Teknik Pengukuran Dimensi dan Penetapan Daya Angkut Kendaraan Barang dari Direktorat Jenderal Perhubungan Darat dan perhitungan Titik Berat Kendaraan Barang. 
3. Pembahasan Muatan Sumbu Terberat dan faktor perusak jalan (damage factor) berdasarkan ketentuan yang sudah diatur dalam Undang-undang, yang kemudian hanya dijadikan sebagai standar pengukuran tingkat kerusakan jalan.

4. Pengukuran titik berat dilakukan pada kendaraan mobil barang jenis mobil bak muatan terbukia konfigurasi sumbu 1.2 dan 1.22 untuk mengetahui persentase berat yang terjadi antara as roda depan dengan as roda belakang.

5. Ketentuan Muatan Sumbu terberat pada kelas jalan yang ada hanya digunakan sebagai parameter pengukuran.

6. Pengukuran beban yang dilakukan pada saat kondisi kendaraan diam.

\section{E. Tujuan Penelitian}

Tujuan penelitian ini adalah sebagai berikut :

1. Mengidentifikasi permasalahan pelanggaran dimensi, muatan kendaraan mobil barang jenis mobil bak muatan terbuka konfigurasi sumbu1.2 dan 1.22agar tidak menyebabkan kerugian baik pada jalan yang dilaluinya (pemerintah) maupun kendaraan barang itu sendiri.

2. Membuktikan bahwa pada kondisi berat muatan yang sama akan menyebabkan perbedaan reaksi muatan sumbu yang terjadi antara gandar depan dan gandar belakang pada kendaraan yang berbeda.

3. Membuat suatu alternatif pemecahan permasalahan untuk bak muatan terbuka sesuai dengan penggunaan pengangkutan barang sesuai klasifikasi barang yang diangkut.

\section{F. Manfaat Penelitian}

Dalam penelitian Pengaruh Dimensi, Muatan terhadap Jumlah Berat Yang Diijinkan Mobil bak Muatan terbuka konfigurasi sumbu 1.2 dan 1.22 ini diharapkan memberikan manfaat antara lain :

1. Sebagai wacana dalam aplikasi ilmu pengetahuan, terutama tinjauan mengenai teknis desain bak muatan terbuka kendaraan mobil barang jenis mobil bak muatan terbuka konfigurasi sumbu 1.2 dan 1.22

2. Memberikan masukan/bahan acuan kepada Pemerintah untuk mendorong meningkatkan kesadaran kepada para pengusaha angkutan barang dalam merencanakan desain kendaraannya dan kepada para pengusaha bak muatan terbuka. 
3. Memberikan pedoman kepada para operator dalam efektifitas pemuatan kendaraan mobil barang yang lebih baik agar tidak melebihi batas muatan.

4. Mengurangi kerusakan jalan akibat overload pada kendaraan mobil barang, khususnya yang disebabkan oleh kendaraan mobil bak muatan terbuka konfigurasi sumbu 1.2 dan $1.22 \mathrm{G}$.

\section{G. Aspek Legalitas}

1. Landasan Hukum

a. Undang - undang nomor 22 Tahun 2009

b. Undang - Undang Nomor 38 Tahun 2004 Tentang Jalan

c. Peraturan Pemerintah Nomor 55 Tahun 2012 tentang Kendaraan

d. Keputusan Menteri Perhubungan Nomor 13 Tahun 2001 tentang Penetapan Kelas Jalan di Pulau Sulawesi

e. Peraturan Pemerintah Nomor 80 Tahun 2012 tentang Tata Cara Pemeriksaan Kendaraan Bermotor di Jalan dan Penindakan Pelanggaran Lalu Lintas dan Angkutan Jalan:

f. Keputusan Menteri Perhubungan Nomor 63 Tahun 1993 tentang Persyaratan Ambang Batas Laik Jalan kendaraan bermotor, kereta gandengan, kereta tempelan, karoseri dan bak muatan serta komponen-komponennya

g. Keputusan Direktur Jenderal Perhubungan Darat Nomor : SK.727/AJ.307/DRJD/2004 tentang Pedoman Teknis Penyelenggaraan Angkutan Barang Umum Di Jalan

h. Surat Edaran Direktorat Perhubungan Darat NO. SE.01/ AJ.307/ DRJD/ 2004, tentang Pengawasan dan Pengendalian Muatan Lebih:

\section{H. Bagan Alir Penelitian}

Agar proses penelitian yang dilakukan lebih terstruktur maka dibuat bagan alir sebagai berikut : 


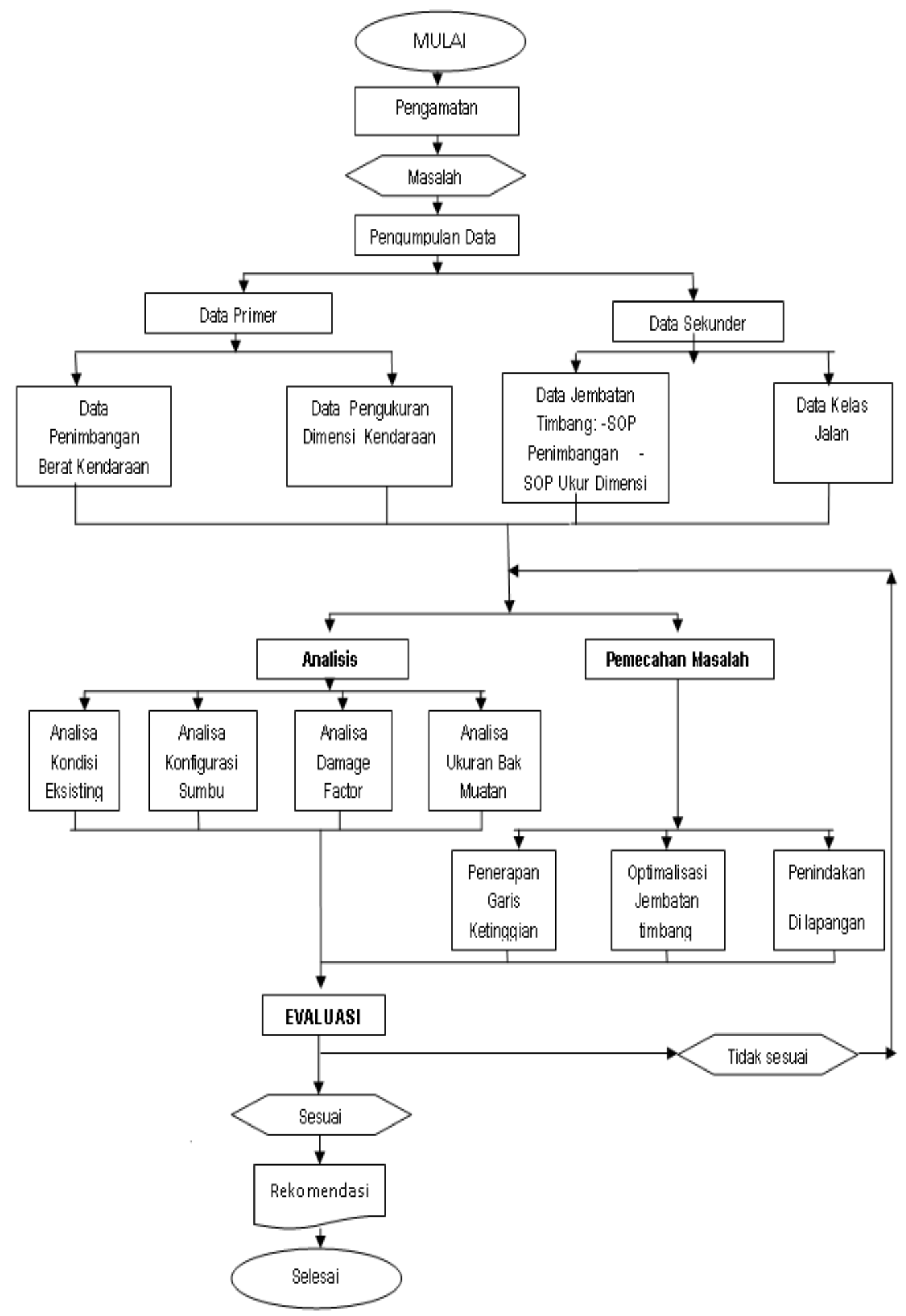

Gambar 1.1 Bagan Alir Penelitian

\section{ANALISIS DAN PEMECAHAN MASALAH}

\section{A. ANALISA}

1. Analisa Kondisi Eksisting 
penentuan pengambilan sampel dalam kategori digunakan dengan jumlah sampel 50.Untuk sampel Kendaraan Mobil Barang Jenis Truk Besar Berkonfigurasi 1.2 dan 1.22 pada Jembatan Timbang Balong Gandu Subang Jawa Barat adalah 50 sampel

2. Analisa Konfigurasi Sumbu dan Titik berat Kendaraan

a. Konfigurasi Sumbu Kendaraan

b. Analisa Dimensi Kendaraan

Setelah melakukan pengamatan dilapangan didapat 3 (tiga jenis) dimensi kendaraan mobil barang jenis truk besar berkonfigurasi 1.2 dan 1.22 menurut dimensi dari bak terbuka, dari ketiga tipe tersebut diambil berdasarkan kesamaan dari jenis dan ukuran dilapangan, sehingga diputuskan untuk mengklasifikasikan ukuran dimensi kendaraan tersebut menjadi 3 (tiga) tipe ukuran. Ukuran bak truk yang akan menjadi fokus analisa tersebut antara lain

1) Tipe ukuran standar (Jenis I)

2) Jenis II

3) Jenis III

Tabel Dimensi Spesifikasi Kendaraan Mobil Barang

\begin{tabular}{|c|c|c|c|c|}
\hline No. & Dimensi & $\begin{array}{c}\text { Jenis } 1 \\
(\mathrm{~mm})\end{array}$ & $\begin{array}{c}\text { jenis } 2 \\
(\mathrm{~mm})\end{array}$ & $\begin{array}{c}\text { Jenis } 3 \\
(\mathrm{~mm})\end{array}$ \\
\hline 1 & Jarak Sumbu Roda (a) & 6080 & 6080 & 6080 \\
\hline 2 & Panjang Bak (b) & 8950 & 9400 & 10050 \\
\hline 3 & Total Panjang Kend (p) & 11065 & 11552 & 12220 \\
\hline 4 & Total lebar & 2450 & 2500 & 2500 \\
\hline 5 & Total Tinggi & 2900 & 3100 & 3300 \\
\hline 6 & Lebar Jejak Roda Depan FR Tr & 2010 & 2010 & 2010 \\
\hline 7 & Lebar Jejak Roda Belakang RR Tr & 1910 & 1910 & 1910 \\
\hline 8 & Julur Depan (FOH) & 1442 & 1442 & 1442 \\
\hline 9 & Julur Belakang (ROH) & 3283 & 3770 & 4438 \\
\hline 10 & Jarak Antara Titik Berat Muatan dengan & 5075 & 5500 & 5825 \\
\hline 11 & Sumbu Depan & $28 \%$ & $28 \%$ & $28 \%$ \\
\hline & Presentase $F O H$ & $62 \%$ & $73 \%$ \\
\hline
\end{tabular}


c. Analisa Persentase Beban Sumbu

Analisa persentase beban sumbu dilakukan di Jembatan Timbang Balong Gandu Subang Jawa Barat.Dalam menghitung reaksi sumbu yang terjadi antara sumbu 1 (satu) atau sumbu depan dan sumbu 2 (dua) atau sumbu belakang untuk konfigurasi 1.2 serta reaksi sumbu 1(satU), sumbu 2(dua) dan sumbu 3(tiga) untuk konfigurasi 1.22 maka perhitungan yang digunakan adalah perhitungan Reaksi Sumbu Kendaraan

Tabel 4. 2. Perbandingan Beban pada Setiap Sumbu

\begin{tabular}{|c|c|c|c|c|}
\hline \multirow{2}{*}{ TONASE } & \multicolumn{2}{|c|}{ JBB } & \multicolumn{2}{c|}{$20760(\mathrm{Kg})$} \\
\hline & & & & \\
JENIS TRUK & DEPAN & BELAKANG & DEPAN & BELAKANG \\
\hline $\begin{array}{c}\text { I } \\
\text { JBI }=12070 \mathrm{~kg}\end{array}$ & 4.070 & 8000 & 5.510 & 15.250 \\
\hline II & 3.570 & 8000 & 4.450 & 16.310 \\
\hline JBI $=11570 \mathrm{~kg}$ & 3.250 & 8000 & 3.650 & 17.110 \\
\hline JII & & & & \\
\hline
\end{tabular}

Sumber : Hasil Analisa

Dari tabel diatas lebih terlihat bagaimana perbandingan beban yang terjadi pada sumbu belakang dengan bebansumbu atau berat kendaraan tersebut sama, akan tetapi tekanan pada gandar belakang antara satu jenis dengan dengan jenis lainnya berbeda. Dengan Jumlah Berat yang di Ijinkan yaitu $14.000 \mathrm{~kg}$, setelah di analisis maka Truk jenis I beban gandar belakangnya adalah $8.000 \mathrm{~kg}$ dan truk jenis II sebesar $8.000 \mathrm{~kg}$ serta truk jenis III sebesar $8.000 \mathrm{~kg}$. Dari tabel 4.2 dan paragraf diatas dapat disimpulkan bahwa dimensi bak muatan terbuka apabila terjadi penambahan dari ukuran pada bak muatan terbuka yang melebihi ukuran standar, maka akan menyebabkan perubahan persentase pada beban gandar yang terjadi pada gandar belakang dan gandar depannya. Dengan berubahnya persentase tersebut menyebabkan besarnya tonase yang terjadi pada gandar belakang hingga melebihi Muatan Sumbu Terberat (MST). 


\begin{tabular}{|c|c|c|c|c|c|c|c|c|c|c|c|c|c|c|c|}
\hline No. & $\begin{array}{c}\mathrm{S} 1 \\
(\mathrm{~kg})\end{array}$ & $\mathrm{S} 2(\mathrm{~kg})$ & $\mathrm{L}(\mathrm{kg})$ & $\begin{array}{c}\mathrm{a} \\
(\mathrm{mm})\end{array}$ & $\begin{array}{c}\mathrm{q} \\
(\mathrm{mm})\end{array}$ & $\mathrm{G}(\mathrm{kg})$ & $\begin{array}{l}\text { JBB } \\
(\mathrm{kg})\end{array}$ & $\begin{array}{c}\mathrm{R} 1 \\
(\mathrm{~kg})\end{array}$ & $\begin{array}{c}\mathrm{R} 2 \\
(\mathrm{~kg})\end{array}$ & $\mathrm{JBI}(\mathrm{kg})$ & $\begin{array}{c}\mathrm{R} 1 \\
(\mathrm{~kg})\end{array}$ & $\begin{array}{c}\mathrm{R} 2 \\
(\mathrm{~kg})\end{array}$ & $\begin{array}{c}\text { Berat } \\
\text { Kendara } \\
\text { an }\end{array}$ & R1 (kg) & R2 ( $\mathrm{kg})$ \\
\hline 1 & 2700 & 1980 & 9140 & 6080 & 5075 & 180 & 14000 & 4390 & 9610 & 12070 & 4070 & 8000 & 12100 & 4230 & 7870 \\
\hline 2 & 2760 & 2000 & 9060 & 6080 & 5500 & 180 & 14000 & 3800 & 10200 & 11570 & 3570 & 8000 & 12600 & 4350 & 7750 \\
\hline 3 & 2810 & 2050 & 8960 & 6080 & 5825 & 180 & 14000 & 3370 & 10630 & 11250 & 3250 & 8000 & 13300 & 4520 & 8780 \\
\hline 4 & 3110 & 2080 & 10130 & 5530 & 4230 & 180 & 15500 & 5670 & 9830 & 13110 & 5110 & 8000 & 13040 & 5080 & 7960 \\
\hline 5 & 3190 & 2130 & 10000 & 6220 & 4610 & 180 & 15500 & 5960 & 9540 & 13420 & 5420 & 8000 & 12870 & 5200 & 7670 \\
\hline 6 & 2650 & 1935 & 10235 & 4280 & 3080 & 180 & 15000 & 5700 & 9300 & 13190 & 5190 & 8000 & 17800 & 7000 & 10800 \\
\hline 7 & 3185 & 1885 & 10750 & 5510 & 4210 & 180 & 16000 & 5900 & 10100 & 13250 & 5250 & 8000 & 18200 & 7210 & 10990 \\
\hline 8 & 3260 & 1950 & 10610 & 6200 & 4620 & 180 & 16000 & 6140 & 9860 & 13510 & 5510 & 8000 & 17150 & 6990 & 10160 \\
\hline 9 & 3130 & 1875 & 10815 & 5510 & 4210 & 180 & 16000 & 5860 & 10140 & 13200 & 5200 & 8000 & 20340 & 8010 & 12330 \\
\hline 10 & 3205 & 1940 & 10675 & 6200 & 4900 & 180 & 16000 & 6100 & 9900 & 12990 & 4990 & 8000 & 19880 & 7640 & 12240 \\
\hline 11 & 2710 & 1955 & 10255 & 4850 & 3650 & 180 & 15100 & 5430 & 9670 & 12880 & 4880 & 8000 & 17600 & 6670 & 10930 \\
\hline 12 & 2502 & 1436 & 9882 & 5500 & 4200 & 180 & 14000 & 5020 & 8980 & 12710 & 4710 & 8000 & 12150 & 4500 & 7650 \\
\hline 13 & 2420 & 1345 & 10055 & 5500 & 4200 & 180 & 14000 & 4980 & 9020 & 12660 & 4660 & 8000 & 11960 & 4400 & 7560 \\
\hline 14 & 2375 & 1325 & 10120 & 4850 & 3650 & 180 & 14000 & 3730 & 10270 & 12750 & 4750 & 8000 & 16270 & 6060 & 10210 \\
\hline 15 & 3285 & 2125 & 9910 & 5530 & 4230 & 180 & 15500 & 5800 & 9700 & 13270 & 5270 & 8000 & 20300 & 8060 & 12240 \\
\hline 16 & 3165 & 2065 & 10090 & 5530 & 4230 & 180 & 15500 & 5720 & 9780 & 13170 & 5170 & 8000 & 16720 & 6560 & 10160 \\
\hline 17 & 3250 & 2020 & 10050 & 6220 & 4610 & 180 & 15500 & 6030 & 9470 & 13520 & 5520 & 8000 & 19430 & 7930 & 11500 \\
\hline 18 & 2700 & 1980 & 9140 & 6080 & 5075 & 180 & 14000 & 4390 & 9610 & 12070 & 4070 & 8000 & 20760 & 5510 & 15250 \\
\hline 19 & 2760 & 2000 & 9060 & 6080 & 5500 & 180 & 14000 & 3800 & 10200 & 11570 & 3570 & 8000 & 20760 & 4450 & 16310 \\
\hline 20 & 2810 & 2050 & 8960 & 6080 & 5825 & 180 & 14000 & 3370 & 10630 & 11250 & 3250 & 8000 & 20760 & 3650 & 17110 \\
\hline
\end{tabular}


d. Analisa Daya Rusak (Damage Factor) Akibat Persentase Beban sumbu dan Beban Lebih Pada Kendaraan Studi

Tabel 4.4 Perhitungan Damage Factor

\begin{tabular}{|c|c|c|c|c|}
\hline \multirow{3}{*}{ JENIS TRUK } & \multicolumn{4}{|c|}{ BEBAN SUMBU } \\
\hline & \multicolumn{2}{|c|}{$14000 \mathrm{~kg}$} & \multicolumn{2}{|c|}{$20760 \mathrm{~kg}$} \\
\hline & $\begin{array}{c}\text { DEPAN } \\
(\mathrm{kg})\end{array}$ & BELAKANG $(\mathrm{kg})$ & $\begin{array}{c}\text { DEPAN } \\
(\mathrm{kg})\end{array}$ & BELAKANG $(\mathrm{kg})$ \\
\hline I $\quad J B I=12070$ & 4070 & 8000 & 5510 & 15250 \\
\hline II $\mathrm{JBI}=11570$ & 3570 & 8000 & 4450 & 16310 \\
\hline \multirow[t]{2}{*}{ III JBI $=11250$} & 3250 & 8000 & 3650 & 17110 \\
\hline & \multicolumn{4}{|c|}{ DAMAGE FACTOR (DF) } \\
\hline I $\quad J B I=12070$ & & 1.17 & & 13.31 \\
\hline II $\quad J B I=11570$ & & 1.11 & & 16.39 \\
\hline III JBI $=11250$ & & 1.05 & & 19.66 \\
\hline
\end{tabular}

Sumber : Hasil Analisis

Dari analisa perhitungan diatas jelas terlihat bahwa metode Bina Marga sudah menghitung tiap Gandar, sehingga dapat diketahui damage factor yang terjadi sebenarnya setiap sumbu.

Tabel 4.5 Hasil Perhitungan Damage Factor

\begin{tabular}{|c|c|c|c|c|c|c|}
\hline No. & Hasil Penimbangan $(\mathrm{kg})$ & R1 (kg) & $\mathrm{R} 2(\mathrm{~kg})$ & DF Binamarga R1 & DF Binamarga R2 & DF Total \\
\hline 1 & 12100 & 4230 & 7870 & 0.37 & 0.85 & 1.22 \\
\hline 2 & 12600 & 4350 & 7750 & 0.43 & 0.81 & 1.24 \\
\hline 3 & 13300 & 4520 & 8780 & 0.50 & 1.36 & 1.86 \\
\hline 4 & 13040 & 5080 & 7960 & 0.78 & 0.88 & 1.66 \\
\hline 5 & 12870 & 5200 & 7670 & 0.85 & 0.78 & 1.63 \\
\hline 6 & 17800 & 7000 & 10800 & 2.86 & 3.04 & 5.90 \\
\hline 7 & 18200 & 7210 & 10990 & 3.13 & 3.32 & 6.45 \\
\hline.. & $\ldots \ldots$. & $\cdots \cdots$ & ......... & …......... & …......... & ….......... \\
\hline 45 & 19130 & 7260 & 11870 & 3.22 & 4.42 & 7.64 \\
\hline 46 & 17980 & 6920 & 11060 & 2.68 & 3.32 & 6.00 \\
\hline 47 & 14400 & 5450 & 8950 & 1.04 & 1.46 & 2.50 \\
\hline 48 & 15010 & 5810 & 9200 & 1.31 & 1.63 & 2.94 \\
\hline 49 & 13860 & 5110 & 8750 & 0.81 & 1.31 & 2.11 \\
\hline 50 & 12930 & 5070 & 7860 & 0.78 & 0.85 & 1.63 \\
\hline
\end{tabular}


e. AnalisaUkuran Bak Muatan Terbuka menurut Massa Jenis Komoditas (dengan menentukan batas ketinggian)Perencanaan ukuran bak muatan terbuka dilakukan untuk mengambil salah satu solusi dari permasalahan kestabilan kendaraan yang terjadi pada pengangkutan dengan menggunakan Truk besar berkonfigurasi 1.2 dan 1.22. Selanjutnya dapat diterapkan dilapangan untuk memudahkan petugas Lalu Lintas Angkutan Jalan atau Kepolisian dalam menertibkan pengangkutan barang dengan menggunakan kendaraan mobil barang jenis truk besar berkonfigurasi 1.2 dan 1.22 ini.Selain itu juga dapat digunakan sebagai bahan pertimbangan dalam perumusan PERDA (Peraturan Daerah) mengenai aturan tentang pengangkutan barang.

1) Analisa Cluster Massa Jenis

Barang-barang yang diangkut oleh kendaraan barang/truk terdiri dari berbagai jenis komoditas dengan massa jenis berbeda-beda, untuk pengelompokan massa jenis.

2) Analisa Massa Jenis dan Perhitungan Tinggi Bak Muatan

Analisa Massa Jenis dilakukan untuk mengetahui massa jenis komoditas yang diangkut oleh Kendaraan Barang Jenis Truk Besar Berkonfigurasi 1.2 dan 1.22. Sehingga dapat digunakan untuk analisa lanjutan dalam menentukan perencanaan bak muatan terbuka untuk truk besar berkonfigurasi 1.2 dan 1.22 yang akan dibuat.Menurut Peraturan Kebijakan Bidang Pengujian Kendaraan Bermotor, Kementrian Perhubungan Direktorat Jenderal Perhubungan Darat, Direktorat Lalu Lintas dan Angkutan Jalan menyebutkan bahwa untuk menentukan Tinggi Bak Muatan dilakukan perhitungan.

Selanjutnya hasil dari perhitungan tinggi bak tersebut disesuaikan dengan pengelompokan massa jenis benda atau komoditas yang diangkut oleh kendaraan mobil barang tersebut.Berikut ini contoh beberapa jenis benda / komoditas yang dihitung dengan rumus perhitungan ketinggian bak muatan berdasarkam massa jenis benda: 
Tabel 4.7 Perhitungan tinggi Bak Muatan Terbuka berdasarkan Massa jenis Sumber : Hasil Analisis

\section{ANALISA DIMENSI TINGGI BAK MUATAN TERBUKA}

\begin{tabular}{|c|c|c|c|c|c|c|c|c|}
\hline NO & NAMA BENDA & $\begin{array}{c}\text { TINGGI BAK } \\
(\mathrm{m})\end{array}$ & NO & $\begin{array}{c}\text { NAMA } \\
\text { BENDA }\end{array}$ & $\begin{array}{c}\text { TINGGI BAK } \\
(\mathrm{m})\end{array}$ & NO & $\begin{array}{c}\text { NAMA } \\
\text { BENDA }\end{array}$ & $\begin{array}{c}\text { TINGGI } \\
\text { BAK(m) }\end{array}$ \\
\hline 1 & Ampas tebu & 3.62 & 31 & Kacang & 0.58 & 61 & Kerikil & 0.29 \\
\hline 2 & Sabun serpih & 2.72 & 32 & Benih & 0.57 & 62 & Asbes & 0.27 \\
\hline 3 & Kapas sekam & 2.26 & 33 & Gandum & 0.57 & 63 & Batu & 0.27 \\
\hline 4 & Arang & 2.09 & 34 & Kentang & 0.57 & 64 & Pasir & 0.27 \\
\hline 5 & Serbuk gergaji & 2.07 & 35 & Minyak & 0.55 & 65 & Pasir dgn & 0.26 \\
\hline 6 & Kacang tanah & 1.60 & 36 & Butir & 0.55 & 66 & Pasir & 0.26 \\
\hline 7 & Tebu & 1.60 & 37 & Kerang & 0.54 & 67 & Gading & 0.24 \\
\hline 8 & Tembakau & 1.36 & 38 & Gambut & 0.54 & 68 & Kerikil & 0.23 \\
\hline 9 & Kelapa & 1.23 & 39 & Sabun & 0.54 & 69 & Pasir air & 0.23 \\
\hline 10 & Gambut & 1.09 & 40 & Cangkang & 0.51 & 70 & Pasir & 0.23 \\
\hline 11 & Pupuk & 1.09 & 41 & Gula & 0.51 & 71 & Kerikil & 0.22 \\
\hline 12 & Cottonwood & 1.04 & 42 & Plester & 0.51 & 72 & Pasir dgn & 0.22 \\
\hline
\end{tabular}

Dari analisa diatas dapat kita ambil suatu kesimpulan bahwa ketinggian bak muatan yang ada dilapangan dengan ukuran panjang standar disesuaikan dengan komoditas muatan yang diangkut oleh kendaraan mobil barang, maka didapat ukuran seperti diatas.Untuk memudahkan mengatasi permasalahan kestabilan kendaraan mobil barang jenis khususnya truk besar berkonfigurasi 1.2 dan 1.22 dilapangan dapat direncanakan dengan merencanakan Batas Ketinggian Muatan pada dinding bak muatan terbuka berdasarkan pengelompokan berat jenis komoditas.Perencanaan batas ketinggian muatan disesuaikan dengan ukuran bak muatan yang ada, dengan asumsi bak muatan standar di bagi menjadi 3 (tiga) batas ketinggian muatan. Pembagian batas ketinggian ini berdasarkan analisa clustermassa jenis komoditas yang telah di analisis diatas.

3) Analisa Kestabilan Kendaraan

Analisa kestabilan kendaraan digunakan untuk mengetahui besar dari gaya normal pada roda kendaraan mobil barang jenis truk besar berkonfigurasi 1.2 pada saat melakukan gerakan membelok yang dipengaruhi oleh berat kendaraan, perpindahan normal karena momen, 
dan perpindahan normal karena pitching, serta kecepatan. Langkahlangkah yang perlu dilakukan dalam perhitungan stabilitas kendaraan mobil barang jenis truk besar berkonfigurasi 1.2 adalah sebagai berikut.

Analisa Penentuan Titik Berat, Analisa dilakukan untuk mengetahui letak titik berat pada kendaraan mobil barang jenis truk besar berkonfigurasi 1.2 dan 1.22 yang didapat dari ukuran dimensi kendaraan.

Tabel 4.8. Titik Berat Kendaraan

\begin{tabular}{|c|c|c|c|c|c|}
\hline No. & $\mathrm{P}(\mathrm{mm})$ & $\mathrm{a}(\mathrm{mm})$ & $\mathrm{q}(\mathrm{mm})$ & $\mathrm{b}(\mathrm{mm})$ & $\mathrm{h}(\mathrm{mm})$ \\
\hline 1 & 12300 & 6080 & 5075 & 435 & 2612 \\
\hline 2 & 12480 & 6080 & 5500 & 392 & 2695 \\
\hline 3 & 12620 & 6080 & 5825 & 365 & 2710 \\
\hline 4 & 11185 & 5530 & 4230 & 1225 & 2685 \\
\hline 5 & 11675 & 6220 & 4610 & 895 & 2695 \\
\hline ..... & .............. & ..................... & …….......... & ……............ & ……........... \\
\hline 45 & 9495 & 4600 & 3450 & 1635 & 2495 \\
\hline 46 & 9895 & 4850 & 3600 & 1610 & 2535 \\
\hline 47 & 12145 & 6020 & 4870 & 475 & 2595 \\
\hline 48 & 11395 & 5600 & 4350 & 1210 & 2590 \\
\hline 49 & 11425 & 5650 & 4400 & 1135 & 2585 \\
\hline 50 & 8875 & 4600 & 3320 & 1665 & 2580 \\
\hline
\end{tabular}

Dari tabel

diatas didapatkan data mengenai letak tiitk berat dari dimensi kendaraan mobil barang jenis truk besar berkonfigurasi 1.2 dan 1.22 Dengan q merupakan jarak antara sumbu depan ke titik berat, b merupakan jarak antara sumbu belakang ke titik berat, $\mathrm{h}$ merupakan tinggi dan $\mathrm{P}$ merupakan Panjang Total darikendaraan mobil barang jenis truk besar berkonfigurasi 1.2.

\section{B. Pemecahan Masalah}

1. Menegaskan Batas Dimensi kendaraan yang Sudah Ditetapkan Seperti pembahasan pada analisa Penentuan Titik Berat diatas maka perlu ditegaskan kembali peraturan mengenai Batas Dimensi kendaraan mobil barang jenis truk besar berkonfigurasi 1.2 dan 1.22. Batas dimensi kendaraan, untuk membatasi panjang julur belakang ( $\mathrm{ROH})$, panjang julur depan $(\mathrm{FOH})$, tinggi muatan agar tetap memenuhi ketentuan pembagian beban kendaraan mobil barang jenis truk besar berkonfigurasi 1.2. Ketentuan batas dimensi telah 
memperhitungkan posisi titik berat dari kendaraan dan pembagian beban pada kedua sumbu kendaraan mobil barang jenis truk besar berkonfigurasi 1.2 dan 1.22, sehingga posisi titik berat dan pembagian beban kendaraan akan berubah jika ada penambahan dimensi, baik panjang, lebar dan tinggi kendaraan.

2. Menerapkan Garis Batas Ketinggian Muatan

Seperti pembahasan pada analisa Massa Jenis dan Perhitungan Tinggi Bak Muatandiatas maka perlu diterapkan Garis batas ketinggian Muatan, untuk membatasi muatan dengan berat jenis yang besar.Perencanaan batas ketinggian muatan disesuaikan dengan ukuran bak muatan yang ada, dengan asumsi bak muatan standar pada kendaraan barang jenis I di bagi menjadi 3 (tiga) batas ketinggian muatan. Pembagian batas ketinggian ini berdasarkan analisa cluster massa jenis komoditas yang telah di analisis diatas.

\section{KESIMPULAN DAN SARAN}

\section{A. Kesimpulan}

Berdasarkan hasil analisis yang telah dilakukan pada kendaraan mobil barang jenis truk besar berkonfigurasi 1.2 dan 1.22 dapat disimpulkan sebagai berikut

1. Pelanggaran dimensi yang terjadi dilapangan setelah dilakukan analisa terdapat kendaraan yang melanggar dalam dimensi khususnya kendaraan jenis III dengan pelanggaran pada dimensi Rear Over Hang yaitu sebesar $4.438 \mathrm{~mm}$ atau sebesar $73 \%$ dari wheelbase.

2. Dari hasil perhitungan terbukti bahwa dengan jumlah muatan yang sama pada kendaraan dengan dimensi yang berbeda, maka nilai beban pada roda juga akan jauh berbeda dalam kestabilan kendaraan. Hasil analisa :

Tabel 5. 2. Perbandingan Beban pada Setiap Sumbu

\begin{tabular}{|c|c|c|c|c|}
\hline TONASE & \multicolumn{2}{|c|}{$\begin{array}{c}\text { JBB } \\
14000(\mathrm{Kg})\end{array}$} & \multicolumn{2}{|c|}{$20760(\mathrm{Kg})$} \\
\hline JENIS TRUK & DEPAN & BELAKANG & DEPAN & BELAKANG \\
\hline I $\quad J B I=12070 \mathrm{~kg}$ & 4.070 & 8000 & 5.510 & 15.250 \\
\hline II $J B I=11570 \mathrm{~kg}$ & 3.570 & 8000 & 4.450 & 16.310 \\
\hline III JBI $=11250 \mathrm{~kg}$ & 3.250 & 8000 & 3.650 & 17.110 \\
\hline
\end{tabular}

Sumber : Hasil Analisa

3. Untuk memudahkan mengatasi permasalahan kelebihan muatan kendaraan mobil barang jenis khususnya truk besar berkonfigurasi 1.2 dan 1.22 dilapangan dapat direncanakan dengan merencanakan Batas Ketinggian Muatan. Batas tinggi bak $0,85 \mathrm{~m}$ digunakan untuk barang curah dan sejenisnya, sedangkan untuk hasil bumi 
dan sejenisnya menggunakan tinggi bak $1,5 \mathrm{~m}$, dan $2 \mathrm{~m}$ untuk batas atas tinggi pada dinding bak muatan terbuka berdasarkan pengelompokan berat jenis komoditas.

4. Maka, apabila terjadi pelanggaran dilapangan harus dilakukan tindakan dengan tegas, untuk di pengujian apabila terjadi pelanggaran dimensi kendaraan harus ditindak bila perlu dilakukan pemotongan dan apabila terjadi pelanggaran kelebihan muatan di jembatan timbang maka barang harus diturunkan.

\section{B. Saran}

1. Adanya ketegasan dari Pemerintah Daerah setempat dalam penindakan terhadap pelanggaran dimensi kendaraan mobil barang;

2. Pengawasan terhadap pelanggaran muatan harus benar-benar dilakukan secara serius oleh pemerintah daerah, khususnya di jembatan timbang;

3. Untuk kendaraan yang melanggar dimensi harus dilakukan penindakan dengan tegas bila perlu di potong, agar tidak terjadi pergeseran titik berat muatan;

4. Peran serta Pemerintah Daerah dalam mengawasi kebijakan Dimensi dan kelaikan jalan kendaraan mobil barang (Pengujian Kendaraan Bermotor).

\section{DAFTAR PUSTAKA}

Kusnandar Erwin, 2009 Karakteristik beban kendaraan operasional;

Wijaya Tony,2007 Analisis Multivariat;

UU No 22 Tahun 2009 tentang Lalu Lintas Angkutan Jalan;

UU No 38 Tahun 2004 tentang Jalan;

Petunjuk teknis dimensi kendaraan pada PP nomor 55 tahun 2012 tentang Kendaraan;

Keputusan Menteri Perhubungan Nomor 63 Tahun 1993 tentang Persyaratan Ambang Batas Laik Jalan kendaraan bermotor, kereta gandengan, kereta tempelan, karoseri dan bak muatan serta komponen-komponennya;

KM No 13 Tahun 2001 tentang Kelas Jalan di Pulau Sulawesi;

KM No 5 Tahun 1995 tentang Penyelenggaraan penimbangan kendaraan barang di jalan;

SK Dirjen Hubdat No SK.727/AJ.307/DRJD/2004 tentang Pedoman Teknis Penyelenggaraan Angkutan Barang di Jalan;

Surat Edaran / SE Dirjen Hubdat No.SE.01/AJ.307/DRJD/2004 tentang Pengawasan dan Pengendalian Muatan Lebih.

Teknik Pengukuran Dimensi \& Penetapan Daya Angkut Kendaraan Bermotor (Ikatan Penguji Kendaraan Bermotor Indonesia) 